\title{
NO. 137
}

JUNE

2020

\section{KEY POINTS}

- In partnership with the Food and Agriculture Organization of the United Nations, the Asian Development Bank developed two freely accessible massive open online courses (MOOCs) to provide statistical capacity building in computer-assisted personal interviewing (CAPI) globally. CAPI typically takes the form of tabletbased survey data collection. One of the courses focused on the CSPro platform; the other on Survey Solutions.

- The two courses, which comprised eight modules of videos, exercises, and quizzes, ran concurrently over 8 weeks in early 2019.

- The 655 students who enrolled from around the world could choose to take one CAPI course or both together

- The CSPro course had a completion rate of $35 \%$, and the Survey Solutions course of 37\% - well above the typical MOOC completion rates of between $2 \%$ and $14 \%$.

- The per-student cost for the MOOCs is estimated to be 7 times lower than equivalent classroom training conducted by $A D B$, as MOOCs significantly reduce logistical, transportation, and personnel costs. Further, the potential to conduct additional rounds of the MOOCs with minimal maintenance costs means that the per capita costs will reduce over time.

- A second round of the two CAPI courses will be launched in midJune 2020. Interested learners can register at: https://forms.gle/ bE7LdqzneuvsTko88.

\section{Massive Open Online Courses for Building Statistical Capacity in Computer-Assisted Surveys}

\author{
Jude David Roque \\ Consultant \\ Asian Development Bank (ADB) \\ Dave Pipon \\ Consultant \\ ADB
}

Anna Christine Durante

Consultant

$\mathrm{ADB}$

\author{
Pamela Lapitan \\ Associate Statistics Officer \\ ADB \\ Lakshman Nagraj Rao \\ Statistician \\ ADB \\ Elisabetta Gentile \\ Economist \\ $\mathrm{ADB}$
}

\section{INTRODUCTION}

Monitoring the Sustainable Development Goals hinges on the availability of timely and high-quality statistics from nationally representative surveys and censuses. However, in developing countries field data collection often relies on pen and paper interviewing, which has limitations in the field and requires manual data entry and extensive data cleaning. These additional steps are likely to affect the timeliness, quality, and availability of survey data.

The digital age has brought about a revolution in survey data collection, with computer-assisted personal interviewing (CAPI) tools gaining traction in developing economies across Asia and the Pacific in recent years. CAPI refers

1 The work has benefited from comments received from numerous colleagues across the Asian Development Bank and the Food and Agriculture Organization of the United Nations (FAO), including Elaine S. Tan, Advisor, Office of the Chief Economist and Director General and Head, Statistics and Data Innovation Unit, Economic Research and Regional Cooperation Department, ADB; and Anthony Burgard, Consultant, FAO Regional Office for Asia-Pacific.
ISBN 978-92-9262-239-8 (print) ISBN 978-92-9262-240-4 (electronic) ISSN 2071-7202 (print) ISSN 2218-2675 (electronic) Publication Stock No. BRF200127 DOI: http://dx.doi.org/10.22617/BRF200127 
to the implementation of surveys using handheld devices such as tablets or mobile phones by field enumerators. Field data are immediately recorded and stored on these devices and transferred to the survey manager on an almost real-time basis via the internet, eliminating the need for manual data entry. Furthermore, CAPI has built-in skip, validation, consistency, and logical checks, which are activated as the enumerator navigates through the questionnaire on the handheld device. This leads to fewer errors in the data sent from the field, which in turn reduces the time taken to produce a clean dataset. Finally, CAPI also incorporates several ancillary features such as collecting images, audio, and global positioning system (GPS) information, which enhances the scope and breadth of data collected from field surveys. These benefits of CAPI have made it the norm for field data collection in most developed economies.

However, developing economies are yet to fully integrate CAPI into their survey data collection and management practices. One of the main reasons cited for the limited adoption of CAPI is the limited capacity in government agencies to program CAPI questionnaires and set up a fully functional data transfer system. To this effect, the Asian Development Bank (ADB) has implemented two regional capacity development technical assistance projects, R-CDTA 8778 and R-CDTA 9018, and trained statisticians in government agencies across the region to implement CAPI in both small-scale and nationally representative surveys. ${ }^{2}$ Both classroom and field training activities were conducted in these projects on all aspects of implementing CAPI, from the programming of questionnaires and training of field supervisors and enumerators to the collecting, transferring, and storing of data.

Yet if the goal is to reach out to more developing economies, traditional statistical capacity building through in-class training may have limited reach due to high per capita costs. ${ }^{3}$ An alternative is to organize online training activities, which have the ability to reach out to a wider set of beneficiaries. The advent of Massive Open Online Courses (MOOCs), in particular, is transforming the landscape of learning and knowledge transfer. Going online has democratized learning, enabling both students and advanced professionals across the world to take courses that are tailored to their interests. ${ }^{4}$ Furthermore, the MOOC approach offers flexibility by allowing learners to access the training course materials at their own convenience, alongside facilitating interactions with fellow learners and instructors through online forums, instant messaging, web-based calls, and numerous other interactive features.

However, MOOCs come with their own set of challenges. First, there is some evidence of low course completion rates for those enrolled in MOOCs. Kizilcec et al. and Seaton et al. find that around $5 \%$ of MOOC students complete the courses. ${ }^{5}$ Meanwhile, Banerjee and Duflo, studying a sample of online courses offered by the University of Pennsylvania, report that only $2 \%-14 \%$ of users showed progress by the end of the course. ${ }^{6}$ They attribute this finding to motivational factors and ability. Next, MOOCs also require learners to have reliable access to the internet, which could be a challenge in developing economies where internet penetration rates are low. Finally, most MOOCs allow students to attain a certificate of completion at a fee. This can serve as an impediment to students from developing countries who may not have the financial resources to pay for the certification. These three broad challenges are further impacted by a lack of quantitative evidence from around the globe on how to encourage students to finish courses online.

\section{ABOUT THE CAPI MOOCS}

In partnership with the Food and Agriculture Organization of the United Nations (FAO), ADB developed two MOOCs as an innovative method of providing statistical capacity building on CAPI to countries around the world. Open edX, an open-source scalable learning platform developed by Harvard University and the Massachusetts Institute of Technology, was utilized as the platform for the two courses. ${ }^{7}$ Open edX allows users and organizations to tailor fit the learning platform to suit their needs by enabling online campuses, instructor-led courses, degree programs, and self-paced courses using a single platform. The two CAPI platforms featured in the courses, Census and Survey Processing System (CSPro) and Survey Solutions, were selected because they are freely available and also widely used by survey practitioners, particularly national statistics offices (NSOs).

2 ADB. Regional: Piloting a Field-Integrated Review and Standardized Tool for Involuntary Resettlement. http://www.adb.org/projects/47297-001/main; and ADB. Regional: Implementing Information and Communication Technology Tools to Improve Data Collection and Management of National Surveys in Support of the Sustainable Development Goals. http://www.adb.org/projects/49342-001/main.

3 The per-capita cost of all training activities conducted in R-CDTA 9018 was $\$ 533.84$. The courses were held in the respective countries and did not require flights or hotel costs except for the CAPI training instructor.

4 There is still a "digital divide," whereby people do not have equal access to IT infrastructure and information, both within and between economies. However, MOOC's are minimizing concerns with access, to the extent possible, and are more inclusive than courses offered by elite institutions which have a high price tag.

5 R. Kizilcec, C. Piech, and E. Schneider. 2013. Deconstructing Disengagement: Analyzing Learner Subpopulations in Massive Open Online Courses. In D. Suthers, K. Verbert, E. Duval, and X. Ochoa, eds. LAK'13: Proceedings of the Third International Conference on Learning Analytics and Knowledge. New York: Association for Computing Machinery; and D.T. Seaton, Y. Bergner, I. Chuang, P. Mitros, and D.E. Pritchard. 2014. Who Does What in a Massive Open Online Course? Communications of the ACM. 57 (4). pp. 58-65.

6 A.V. Banerjee and E. Duflo. 2014. (Dis)Organization and Success in an Economics MOOC. American Economic Review. 104 (5). pp. 514-518.

7 Open edX has deployed over 20,000 courses since 2014, reaching out to over 40 million learners. Open edX. http://open.edx.org/. 
CSPro, which has been available since 2000, was developed by the US Census Bureau primarily to edit, process, and disseminate census and survey data. ${ }^{8}$ CSPro is used by most NSOs in developing economies for data entry and batch editing of paper questionnaires. The Android version of CSPro was launched in 2014, and has gained significant traction, particularly in countries where it was already being used for data entry and editing. It serves as the prime software for the implementation of important global surveys such as the Demographic and Health Survey and Multiple Indicator Cluster Survey. CSPro is known for its ability to handle simple as well as complex functions and is fully customizable. CSPro supports data collection on Android devices and questionnaires can be set up offline.

Survey Solutions is a platform developed by the World Bank which aims at assisting governments, NSOs, and nongovernment organizations in the implementation of advanced surveys using mobile devices. ${ }^{9}$ The platform has been available for public use since 2013 and is used to conduct globally relevant surveys such as the Living Standards Measurement Study. It is user-friendly, easy to learn, and capable of handling complex surveys. It has advanced features like plot area mapping and permits online data collection using a web interface, alongside capturing data through phone interviews, and/or conducting cost efficient mixed mode surveys.
In contrast to CSPro, the questionnaire can only be set up online using a web browser.

The development phase of the MOOCs took about 9 months from April 2018 to January 2019 (Figure 1). The first 5 months of the development phase were devoted to drafting the course outline, creating the course modules, and assessing all course materials in preparation for shooting the lecture videos. The actual video shoot took place over a period in the last 2 weeks of September where all the materials prepared in the first 5 months were captured on video. Between October and December, these videos were edited, reviewed, and prepared for final uploading with other materials on Open edX. Meanwhile, preregistration to the course was launched via Google forms in the fourth quarter of 2018. Between this time and the launch of the MOOC on 28 January 2019, a final assessment of the course materials was conducted, and individuals who preregistered on the Google forms were invited to officially enroll onto the MOOC platform. The MOOCs were designed with two separate tracks, one that focused on CSPro and the other that focused on Survey Solutions; students had the option to take either track or pursue both in tandem.

The courses were heavily marketed across various channels including presentations at international statistical meetings,

Figure 1: Timeline of Activities

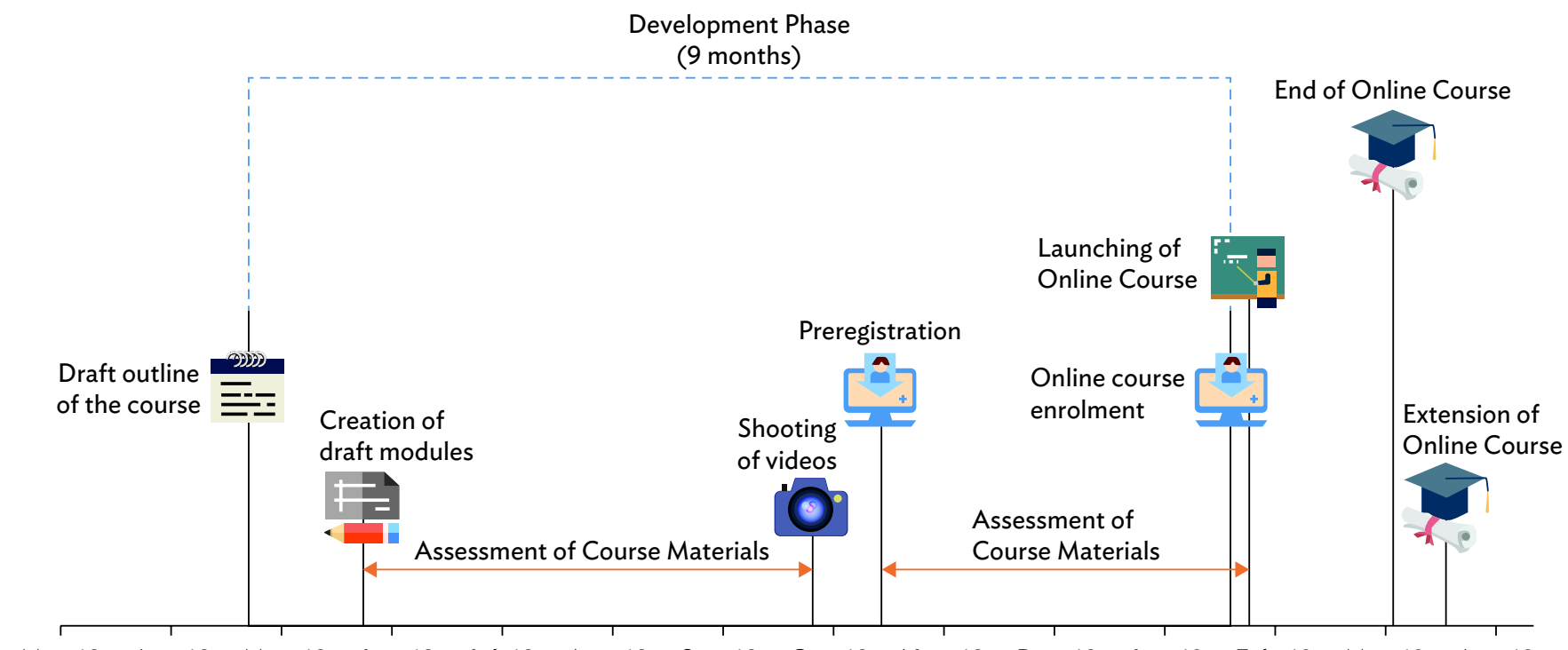

Mar-18 Apr-18 May-18 Jun-18 Jul-18 Aug-18 Sep-18 Oct-18 Nov-18 Dec-18 Jan-19 Feb-19 Mar-19 Apr-19

Source: Asian Development Bank staff and consultant. 2018.

United States Census Bureau. Census and Survey Processing System (CSPro). https://www.census.gov/data/software/cspro.html.

Survey Solutions. https://mysurvey.solutions/. 
via social media, messages within professional statistical networks, and by word of mouth. Promotional videos and digital flyers were very helpful in generating interest in the course. To create incentives for students to enroll in the two courses, it was decided that the four students with the best performance in the courses would be invited to participate and serve as resource persons in a CAPI workshop in Bangkok, Thailand.

The marketing campaign was very successful, with 655 individuals from at least 69 countries enrolling in at least one of the two courses. One-third enrolled only in the CSPro course, while over $18 \%$ enrolled only in the Survey Solutions course. Nearly half of the students (48\%) enrolled in both courses, indicating the popularity of both platforms.

\section{Course Structure}

In terms of course structure, the MOOCs featured mostly identical and parallel modules across both tracks, CSPro and Survey Solutions. ${ }^{10}$ Table 1 provides a breakdown of the online course structure across both tracks. The two courses ran over an 8-week period from 28 January to 22 March 2019, covering eight modules. The original end date of the course was set to 8 March 2019, but a 2-week extension was granted until 22 March 2019 to incentivize students who were close to finishing but needed a little more time. Two new modules were released per week, such that by week 4 , all modules were available to all students. Each module was composed of lecture videos; short exercises in between; and a quiz at the end of the module, which formed the basis for determining the final grade of learners.

Students who completed all eight modules for either track and attained an overall average score of $75 \%$ were given the opportunity to pursue an optional capstone assignment. The capstone assignment required the development of a student's own questionnaire on a platform of their own choice. Students enrolled in both courses were permitted to submit capstone assignments for either or both tracks. The top two students per track with the highest cumulative grade and the highest score for the capstone were invited to participate at a regional dissemination workshop in Bangkok to present their projects and talk about their experiences in taking the MOOC.

\section{Learner Profile}

Overall, the CSPro courses achieved completion rates of $35 \%$ and Survey Solutions courses rates of 37\% (Figure 2). ${ }^{11}$ These percentages are well above the typical completion rates of MOOCs cited in the literature (footnotes 5 and 6).

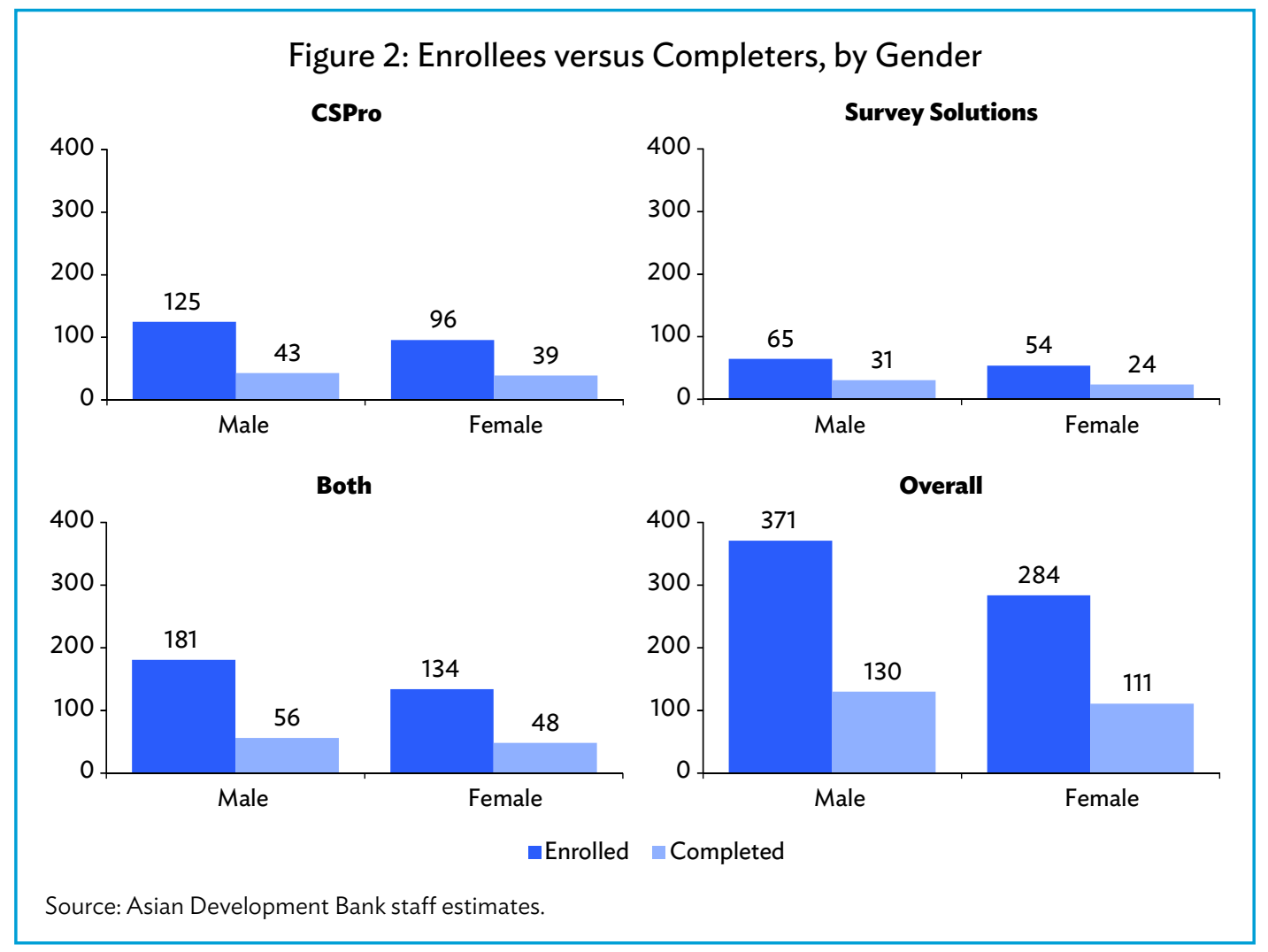

10 The minor differences were due to differences in how the platforms are designed, which made it important to present certain concepts in a different order across the two platforms.

11 The individual percentages include learners that enrolled in both courses. 
Table 1: The Online Course Structure

\begin{tabular}{|c|c|c|}
\hline Module & CSPro & Survey Solutions \\
\hline 1 & \multicolumn{2}{|c|}{$\begin{array}{l}\text { Module } 1 \text { is identical for both tracks and introduced CAPI to the learners. Topics such as CAPI workflows, hardware requirements, } \\
\text { and CAPI experiences were featured. }\end{array}$} \\
\hline 2 & $\begin{array}{l}\text { Introduced the learner to: } \\
\text { - CSPro dataflows } \\
\text { - CSPro question types } \\
\text { - Setting up a data dictionary } \\
\text { - Creaters } \\
\text { - Setting forms } \\
\text { - Send testing on tablet }\end{array}$ & $\begin{array}{l}\text { Introduced the learner to the Designer Tool interface. Students learned } \\
\text { about: } \\
\text { - The use of Designer and Tester applications } \\
\text { - Setting up static texts, images, and questions } \\
\text { - Fixed, nonfixed, sub-, and linked rosters }\end{array}$ \\
\hline 3 & $\begin{array}{l}\text { Discussed skips in CSPro. Specifically, students were } \\
\text { exposed to: } \\
\text { - Skips for multiple-select questions } \\
\text { - Skips for nonfixed rosters } \\
\text { - Skips for fixed rosters }\end{array}$ & $\begin{array}{l}\text { Tackled skips or enabling conditions in Survey Solutions. Students } \\
\text { learned about: } \\
\text { - Logical operators and multi-select questions } \\
\text { - System generated variables } \\
\text { - LINQ expressions } \\
\text { - Enabling rosters and skips for rosters }\end{array}$ \\
\hline 4 & $\begin{array}{l}\text { Students learned how to set validations. Specifically: } \\
\text { - Validations based on previous questions } \\
\text { - Date validations } \\
\text { - Common types of validations used } \\
\text { - Multiple value sets } \\
\text { - Setting up and querying a lookup table }\end{array}$ & $\begin{array}{l}\text { Students learned how to set up validations with the Designer Tool. } \\
\text { Specifically: } \\
\text { - Validations based on previous questions } \\
\text { - Data validations } \\
\text { - Common types of validations in social research } \\
\text { - Cascading combo lists } \\
\text { - Setting up and querying a lookup table }\end{array}$ \\
\hline 5 & $\begin{array}{l}\text { Introduced students to languages and synchronization } \\
\text { features: } \\
\text { - Setting up CSPro to synchronize data back to cloud } \\
\text { - Installing CSEntry for fieldwork } \\
\text { - Deploying CAPI system to CSEntry } \\
\text { - Exporting data }\end{array}$ & $\begin{array}{l}\text { Students learned about the Headquarters tool in Survey Solutions, } \\
\text { specifically looking at: } \\
\text { - Multilanguage surveys } \\
\text { - Setting up user accounts } \\
\text { - Setting up interview application on tablets } \\
\text { - Importing questionnaires to headquarters and creating assignments } \\
\text { - Collecting data on the interview app and synchronizing }\end{array}$ \\
\hline 6 & $\begin{array}{l}\text { Discussed quality control measures: } \\
\text { - Quality control tables } \\
\text { - Batch editing to check for errors } \\
\text { - Paradata }\end{array}$ & $\begin{array}{l}\text { Discussed quality control measures: } \\
\text { - Approving and rejecting cases } \\
\text { - Survey metadata } \\
\text { - Updating questionnaire after fieldwork starts }\end{array}$ \\
\hline 7 & $\begin{array}{l}\text { Discussed advanced features of CSPro: } \\
\text { - Timestamps } \\
\text { - GPS and photo collection } \\
\text { - Dynamic value sets } \\
\text { - Bluetooth synchronization and menu applications } \\
\text { - Language applications and progress reports } \\
\text { - Multilevel applications }\end{array}$ & $\begin{array}{l}\text { Discussed advanced features of Survey Solutions: } \\
\text { - Question scope feature } \\
\text { - Timestamps } \\
\text { - GPS and geography questions } \\
\text { - Computer-assisted web interviewing (CAWI) } \\
\text { - Using variables and randomization in the Designer tool }\end{array}$ \\
\hline 8 & $\begin{array}{l}\text { Showed students how to access and use help and } \\
\text { support features of CSPro. Specifically: } \\
\text { - Inbuilt help in CSPro } \\
\text { - Online support forum for CSPro }\end{array}$ & $\begin{array}{l}\text { Went through the help and support features of Survey Solutions: } \\
\text { - Support portal } \\
\text { - System updates and new features } \\
\text { - How to contact support }\end{array}$ \\
\hline
\end{tabular}

Source: Based on the outline of the Asian Development Bank R-CDTA 9018 Online Training Course.

Examining the enrollment versus actual completion profile by student characteristics generates some informative insights. Attrition is higher for students who enrolled just in the CSPro course versus those only enrolled in the Survey Solutions course, with about $37 \%$ of enrollees completing CSPro and
$46 \%$ completing Survey Solutions courses. This is likely attributable to CSPro being slightly more programming-intensive than Survey Solutions. For the cohort enrolled in both tracks attrition was higher, with nearly $33 \%$ of the enrollees finishing both courses. This indicates that pursuing both courses simultaneously 
was intensive, but the percentage difference between completers of the CSPro course alone versus those completing both the CSPro and Survey Solutions courses is less than $5 \%$.

Figure 2 presents a breakdown of the number of enrollments versus completion by gender of the student. Although more male students enrolled overall than female students, a greater percentage of female students (39\%) completed either or both the courses compared to male students (35\%). A greater percentage of female students that enrolled only in the CSPro track completed the course, while the opposite is true for the Survey Solutions track. For those students enrolled in both tracks, a pattern similar to CSPro for completion rates across gender is observed.

In terms of age, while more from the "over 32" age bracket enrolled only in the CSPro track, only one-third of this group completed the course (Figure 3). In contrast, nearly half of the "32 and younger" cohort completed only the CSPro course. Out of those enrolled solely in the Survey Solutions track, not only was enrollment greater in the "over 32" age group, but more students also completed the course. For those enrolled in both tracks, a larger number came from the "32 and younger" group. This group also had a higher completion rate compared to the "over 32" group (35\% versus 31\%). The younger group might have had more time outside their regular routines to allow them to finish the coursework for both tracks, which could account for the slightly higher completion rates. ${ }^{12}$

Nearly $83 \%$ of the enrolled students either had a bachelor's or master's degree (Figure 4). While one-third of the enrolled students in the CSPro course with a master's degree completed the course, half of the enrolled students in the CSPro course with a bachelor's degree completed the course. This pattern is reversed in the case of the Survey Solutions course, wherein 55\% of master's degree holders completed the course, while $37 \%$ of the

\section{Figure 3: Enrollees versus Completers, by Age}

\section{CSPro}

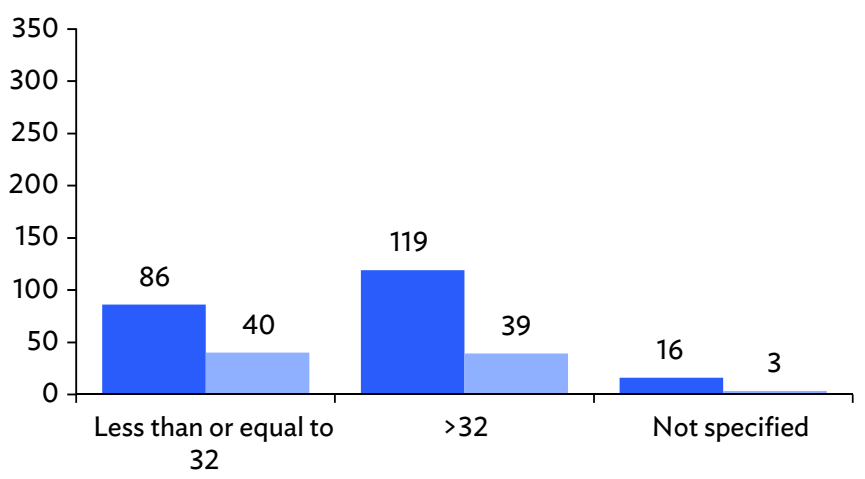

Both

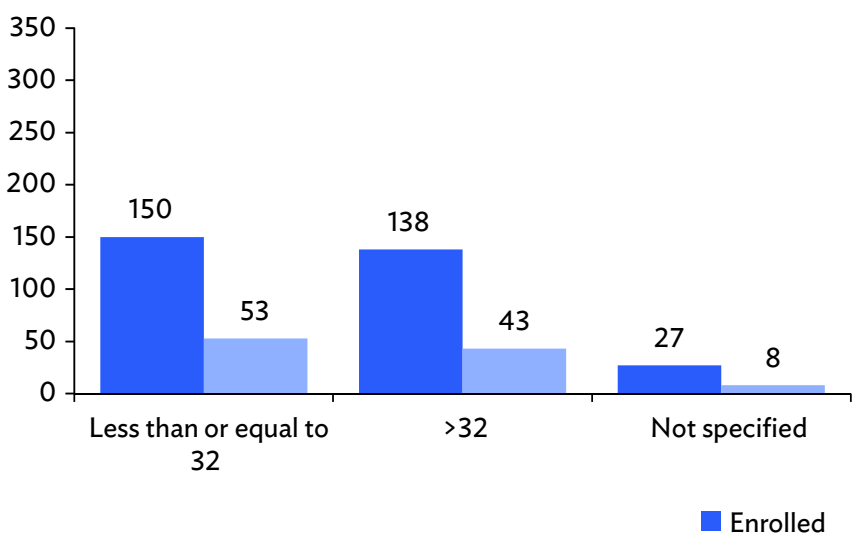

Survey Solutions

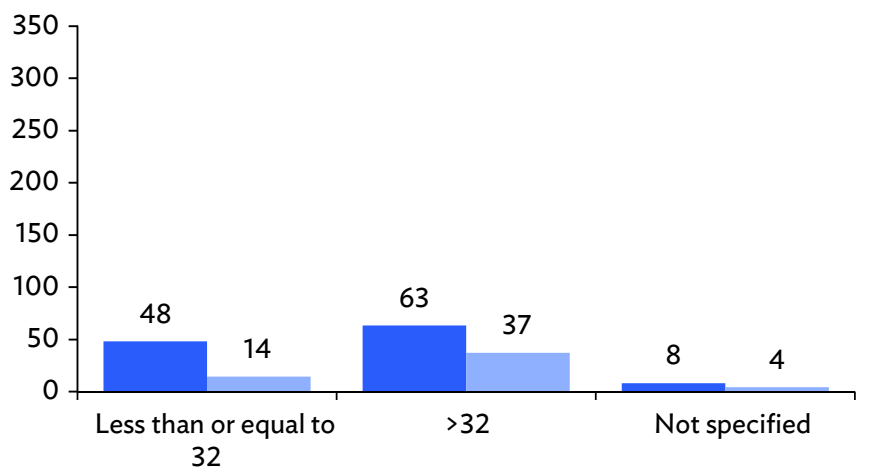

Overall

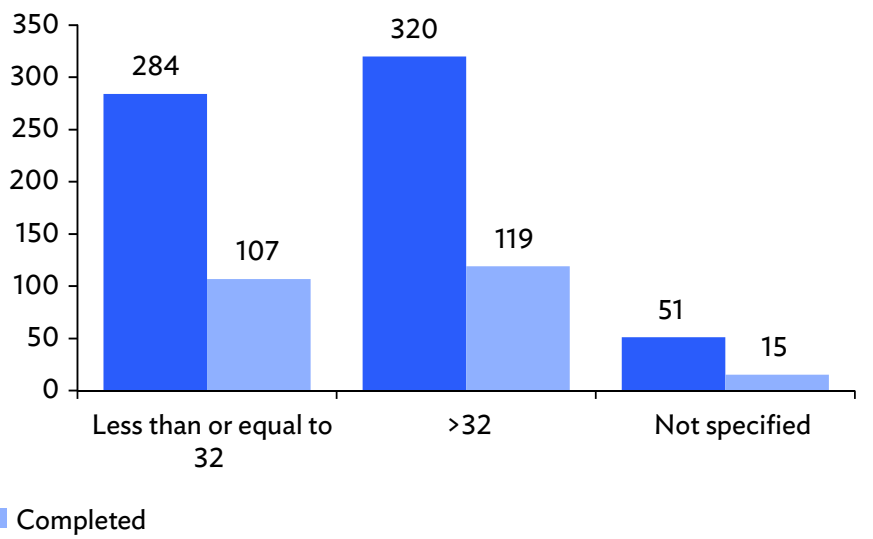

Source: Asian Development Bank staff estimates.

12 Younger learners may also benefit more from CAPI programming certificates for their careers, whereas older professionals may not have that pressing need. 


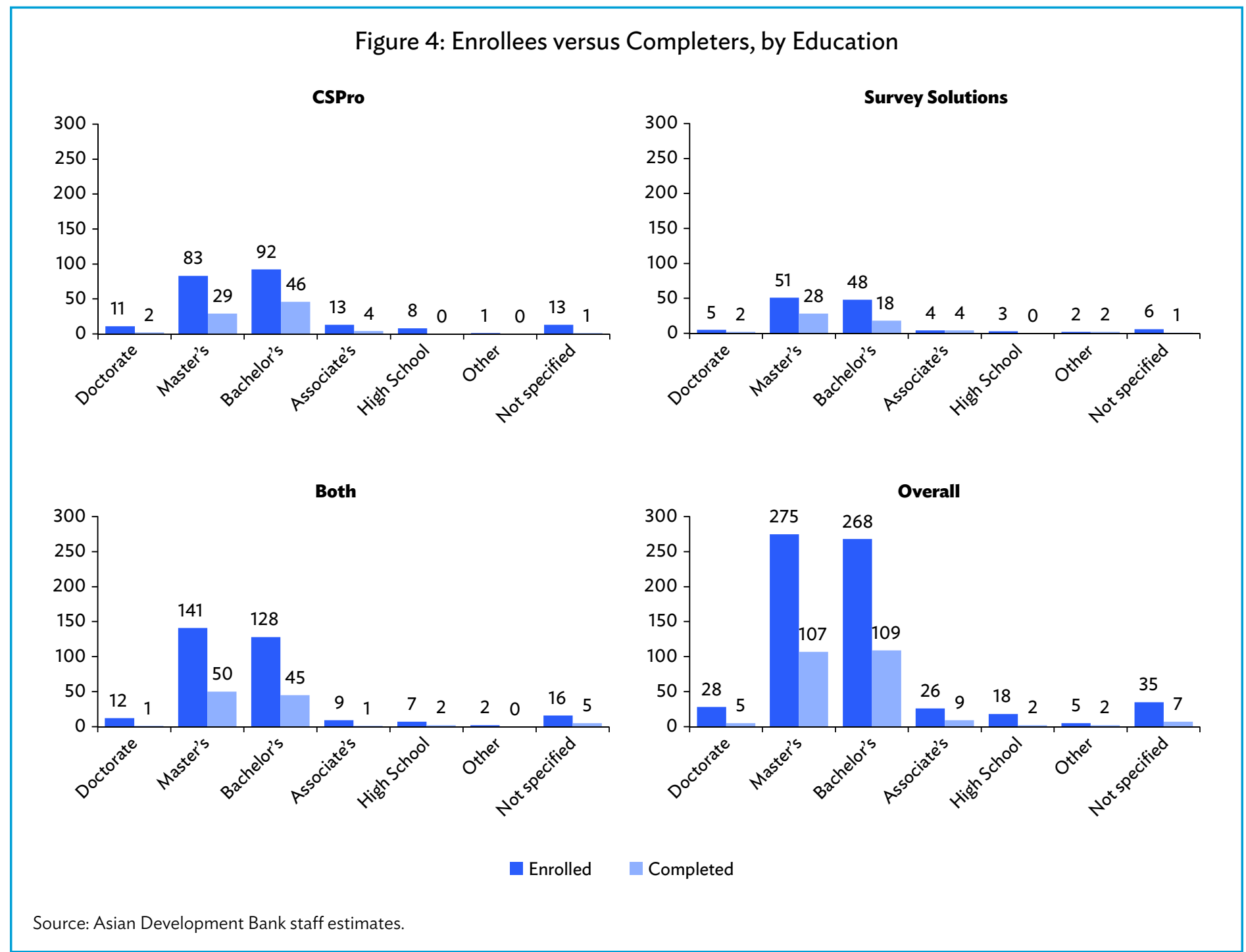

students with a bachelor's degree completed the course. For the cohort that chose to enroll in both tracks, there is no significant difference in completion rates for either bachelor's or master's degree holders.

Given that the course was heavily marketed within the international development statistics community, it is not surprising that the highest enrollment and completion rates came from NSOs (Figure 5). Furthermore, nearly $46 \%$ of the enrolled students came from either NSOs or other government agencies, which is in line with our objective of reaching out to key players in national statistics systems. Academia, which includes students and professors, had the second highest enrollment rate overall, accounting for $22 \%$ of all enrollments. About $8 \%$ of enrollees did not declare their affiliation.

In terms of region of origin, across all cohorts, the top region based on enrollments was Southeast Asia, followed by Africa,
South Asia, and the Pacific (Table 2). For those who only took CSPro, Southeast Asia had the highest completion rate of $52 \%$. Although Africa had the second highest enrollment rate in the CSPro-only track, high attrition was observed, with only $19 \%$ completing the course. A similar pattern was observed in South Asia with an 18\% completion rate for the CSPro-only track. Meanwhile, one-third of the enrollees from the Pacific completed the CSPro course successfully. For those enrolled only in Survey Solutions, South Asia had a completion rate of $64 \%$, significantly higher than the same cohort for CSPro. Africa's completion rate is threefold for Survey Solutions compared to CSPro. For the cohort that took both tracks, Southeast Asia still had the largest number of enrollees, with slightly over one-third of the enrolled students completing both courses. Africa had the second largest number of enrolments, albeit with only one-fifth completing both courses. South Asia exhibited an overall completion rate of $43 \%$, while $41 \%$ of students in the Pacific completed either or both of the courses. 


\section{Figure 5: Enrollees versus Completers, by Organization Type}

CSPro

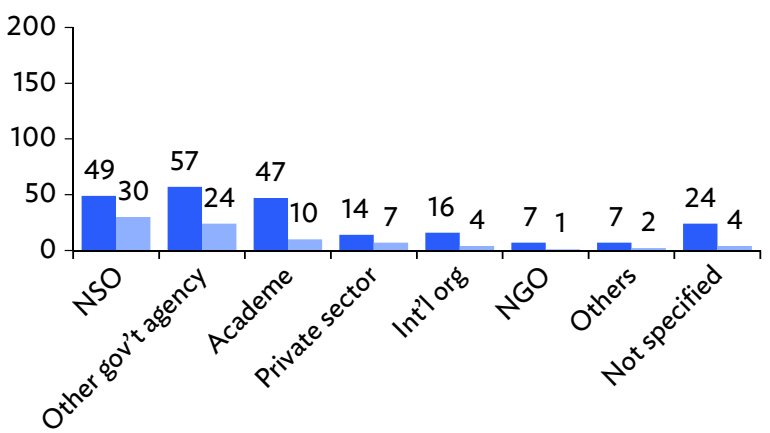

Both

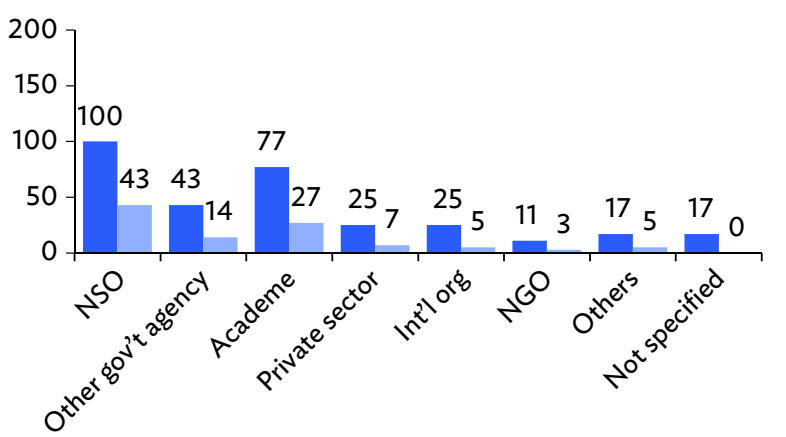

Enrolled
Survey Solutions

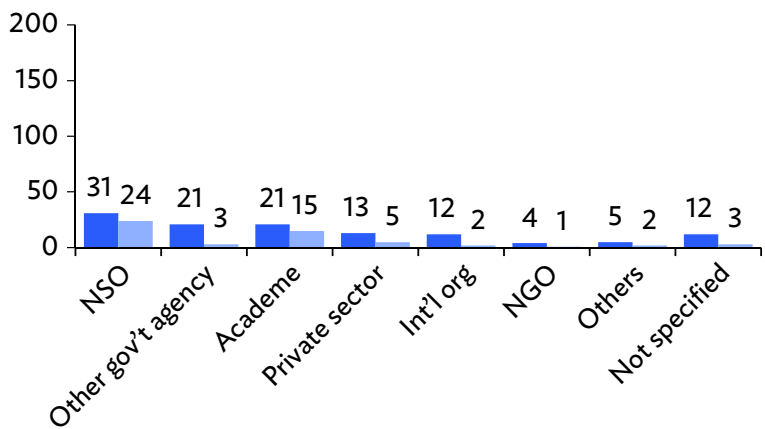

Overall

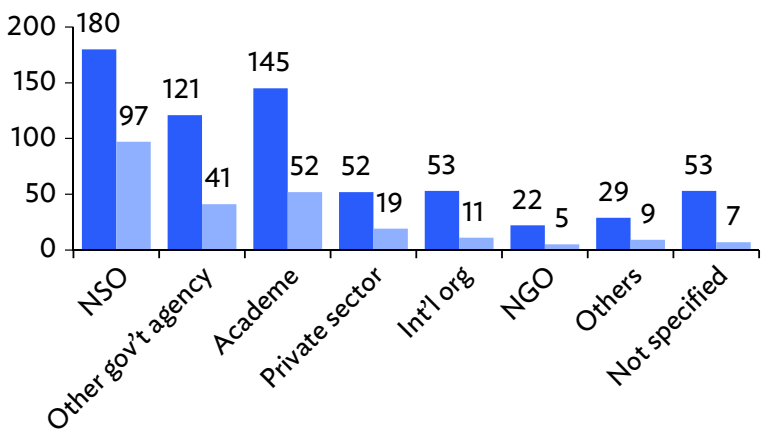

Int'l org = international organization, NGO = nongovernment organization, NSO = national statistics office.

Source: Asian Development Bank staff estimates.

Table 2: Enrollees versus Completers by Region

\begin{tabular}{|c|c|c|c|c|c|c|c|c|c|c|c|c|}
\hline \multirow[b]{3}{*}{ Region } & \multicolumn{4}{|c|}{ Enrollment } & \multicolumn{4}{|c|}{ Completers } & \multicolumn{4}{|c|}{ Completion Rate (in \%) } \\
\hline & CSPro & Suso & Both & Overall & CSPro & Suso & Both & Overall & CCDro & Suse & Roth & Ovarall \\
\hline & Freq & Freq & Freq & Freq & Freq & Freq & Freq & Freq & לוזיתל & suso & Dotn & Uverall \\
\hline Southeast Asia & 112 & 42 & 171 & 325 & 58 & 17 & 59 & 134 & 51.79 & 40.48 & 34.50 & 41.23 \\
\hline Africa & 43 & 23 & 51 & 117 & 8 & 14 & 10 & 32 & 18.60 & 60.87 & 19.61 & 27.35 \\
\hline South Asia & 22 & 22 & 46 & 90 & 4 & 14 & 21 & 39 & 18.18 & 63.64 & 45.65 & 43.33 \\
\hline Pacific & 18 & 11 & 17 & 46 & 6 & 4 & 9 & 19 & 33.33 & 36.36 & 52.94 & 41.30 \\
\hline Europe & 2 & 3 & 6 & 11 & 1 & 2 & 3 & 6 & 50.00 & 66.67 & 50.00 & 54.55 \\
\hline Central Asia & 2 & 5 & 2 & 9 & 0 & 0 & 0 & 0 & 0.00 & 0.00 & 0.00 & 0.00 \\
\hline North America & 1 & 2 & 2 & 5 & 1 & 1 & 0 & 2 & 100.00 & 50.00 & 0.00 & 40.00 \\
\hline East Asia & 2 & 1 & 2 & 5 & 0 & 1 & 0 & 1 & 0.00 & 100.00 & 0.00 & 20.00 \\
\hline South America & 2 & 2 & 1 & 5 & 1 & 1 & 1 & 3 & 50.00 & 50.00 & 100.00 & 60.00 \\
\hline West Asia & 0 & 0 & 1 & 1 & 0 & 0 & 1 & 1 & 0.00 & 0.00 & 100.00 & 100.00 \\
\hline Not specified & 17 & 8 & 16 & 41 & 3 & 1 & 0 & 4 & 17.65 & 12.50 & 0.00 & 9.76 \\
\hline
\end{tabular}

Freq $=$ frequency, Suso $=$ Survey Solutions .

Source: Asian Development Bank staff estimates. 


\section{Figure 6: Odds Ratio}

Type of Organization, Int'l Org to NSOs

Type of Organization, NGO to NSOs

Type of Organization, Academe to NSOs

Type of Organization, Other gov't agency to NSOs

Type of Organization, Others to NSOs

Type of Organization, Not specified to NSOs

Sex: Male to Female

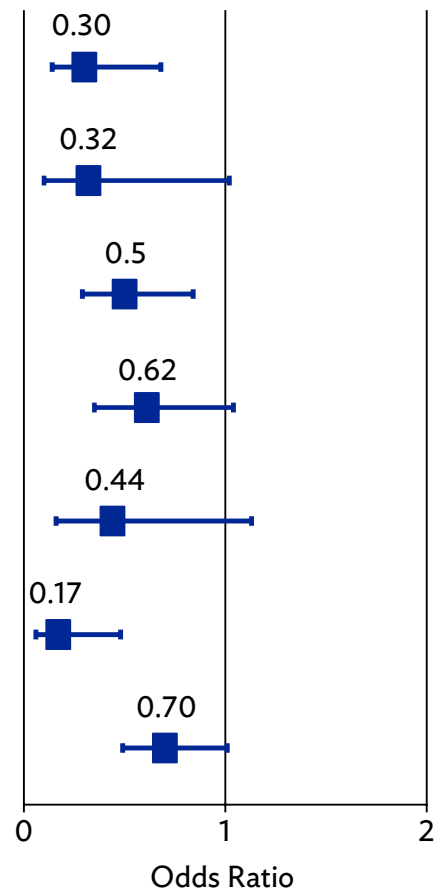

Int'l org = international organization,

NGO = nongovernment organization, NSO = national statistics office Source: Asian Development Bank staff estimates.

To examine the factors that most influenced completion rates, odds ratios were calculated and are presented in Figure $6 .^{13}$ The two characteristics that showed up as statistically significant are organization and gender. In terms of organization, the ratios show that compared with the other organization types specified, more students from NSOs completed the course. For instance, the Academe to NSOs ratio suggests that for every five students that completed from academia, 10 students from NSOs completed either or both of the courses. For every seven male students that completed either or both of the courses, 10 females completed either or both.

\section{COMPLETION AND PROGRESS TIMELINE}

Figure 7 presents the student progress timeline to completion over the duration of the MOOC. By the end of week 1, for both tracks, around $37 \%$ of the students finished the first two modules. By the end of week 4 , when all eight modules had been released, $11 \%$ of the students enrolled in the CSPro track and 12\% of the students enrolled in the Survey Solutions track finished all the modules in either or both tracks.

A 2-week reminder for the deadline of the course was also sent out at the end of week 4. This was followed by a spike in completion rates for those who had reached Modules 4-7. By the end of week 5, completion rates had gone up to 19\% for CSPro and $22 \%$ for Survey Solutions. Given that the end of week 6 marked the original end of course date of 8 March 2019, students who by that time had reached Modules 4-7 might have felt the urgency to complete the courses. This manifested in an additional spike in completion rates to 30\% for CSPro and 31\% for Survey Solutions.

A 2-week extension was subsequently announced after the original end date of 8 March 2019. This was accompanied by a rise in completions, although the jump was not as dramatic as after the first reminder. However, the extension brought about an increase in overall completion rates of about $6 \%$ for both CSPro and Survey Solutions. The overall completion rates achieved were 35\% for CSPro and 37\% for Survey Solutions courses.

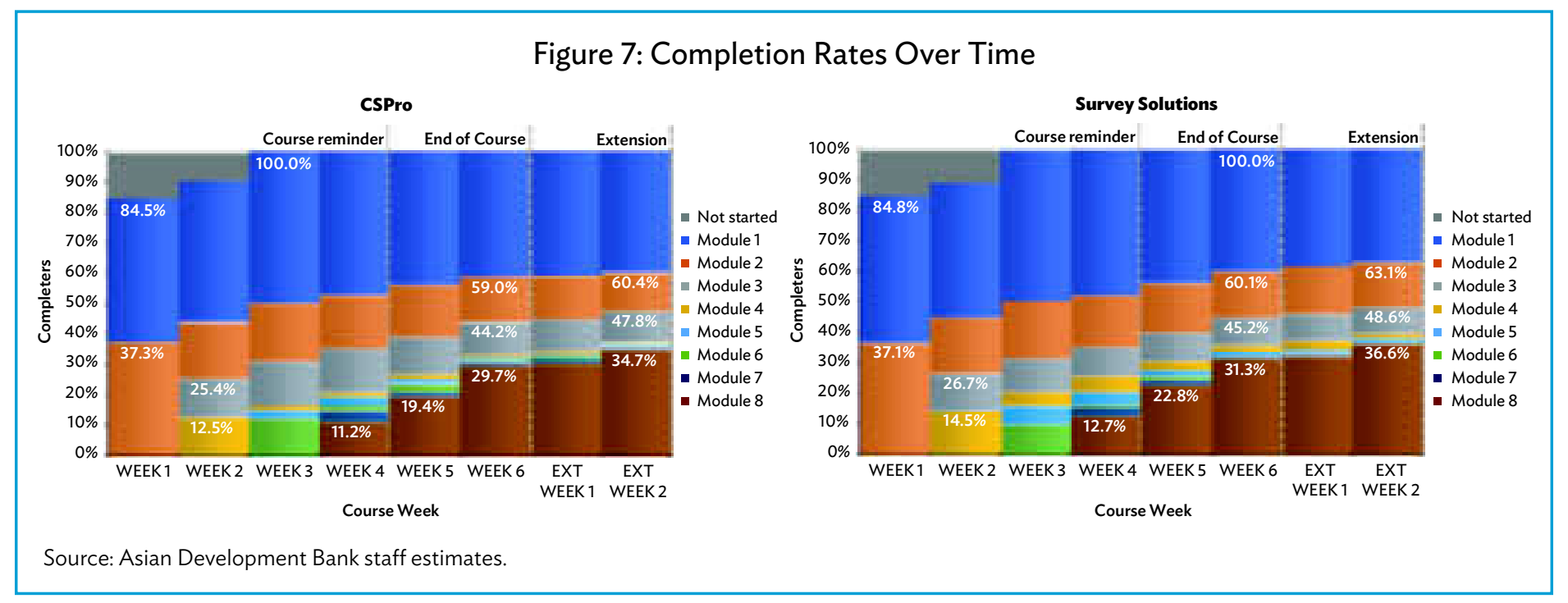

13 While the odds ratio estimates are not causal, they support the associations observed in the figures presented earlier. 
Out of 655 students that enrolled, $8 \%$ or 51 students completed all the module requirements and also submitted a capstone project. Furthermore, 21\% of the Survey Solutions and $11 \%$ of the CSPro completers submitted a capstone assignment. This suggests that the financial incentive to fly to Bangkok was successful and should be considered in future implementation of these courses. More research might be required to test variations of financial and nonfinancial incentives and their relative impact on completion rates.

\section{Student Perception and Feedback}

A course assessment survey was implemented in order to understand student perception of the two MOOCs. Out of those that responded to the course assessment survey, over $90 \%$, or 146 out of 161 for CSPro and 129 out of 138 for Survey Solutions, found the lectures to be clear and organized. Similarly, nearly $90 \%$ of the survey respondents expressed that the video demonstrations helped them better understand the lecture materials. Finally, nearly $80 \%$ of the survey respondents felt that there were sufficient opportunities available for active participation in the two MOOC courses. The course assessment survey also allowed students to rate their overall satisfaction level using a scale from 1 to 10 , with 10 reflecting the greatest level of satisfaction. Across the two tracks, over $80 \%$ of survey respondents gave a score of at least 8 for both courses.

The course assessment survey also revealed the top two reasons why some students lagged behind: (i) being busy with work and household activities; and (ii) poor internet facilities, which made the video watching experience difficult.

Direct feedback was also provided by the students to the instructor, revealing what worked for each platform as well as the challenges that were faced. Some of the things that worked for one platform were seen to be challenges in the other. For instance, favorable feedback was given on the ability of CSPro to develop questionnaires and also transfer them to tablets without relying on an internet connection during the development phase. On the other hand, students noted that one of the challenges of Survey Solutions is that the development of questionnaires and the transferring of them to tablets required an internet connection, since the platform is browser-based. Meanwhile, what worked for Survey Solutions was the ease in programming and implementing the skips and validations, compared to CSPro.

Other recommendations given by the students included the provision of subtitles or transcripts for students who are not native English speakers. There were suggestions to include more scenario-based questions to give more hands-on experience with CAPI in the field. Next, a longer time frame for the full course was suggested by students, given their busy work schedules. Finally, a second iteration of the courses was requested.

\section{Costs}

Developing an online course has significant cost advantages over classroom training. For a total of 655 students, the per capita cost of conducting the online courses was $\$ 78-$ well below the per capita costs of in-class training courses of a similar nature that were conducted as part of the aforementioned technical assistance activities, estimated at $\$ 539$. Furthermore, with future rollouts of the online courses per capita costs are expected to fall even farther, as this will only entail updating the course content to keep up with newer versions of the platforms, as opposed to incurring logistical, transportation, and personnel costs associated with setting up additional rounds of in-class training. In contrast, per capita costs of in-class trainings are expected to increase with the number of participants.

\section{CONCLUSION}

ADB and FAO developed two MOOCs as a novel way to enhance statistical capacity globally on CAPI for two platforms-CSPro and Survey Solutions. With 655 enrollments for the two courses around the globe, a general completion rate of around $37 \%$ which is significantly higher than other similar studies, and overall positive feedback from the students, we find that these MOOCs were an effective way of reaching out to a wider audience. Collating the feedback from the students, as well as analyzing the student completion and performance data, generated some useful recommendations:

(1) MOOCs have the ability to significantly widen the scope for training and building capacity of more individuals across many countries. Even for niche topics, MOOCs will ultimately be more learning, time, and cost effective than inclass training. In our case, we were able to reach out to 655 learners across 69 countries, at substantially lower per capita costs than in-class statistical capacity building activities.

(2) Strategic partnerships with other agencies to develop MOOCs on topics that are of mutual interest not only permit an optimal use of resources, but also facilitate tapping into each agency's networks to reach out to a wider audience. In the case of the two CAPI courses, $\mathrm{ADB}$ and $\mathrm{FAO}$ mutually benefited from this collaboration, which led to an increase of nearly $37 \%$ in enrollments from students outside Asia and the Pacific.

(3) MOOCs may enable reaching out to under-served groups such as women or learners from low-income or lower middle-income economies. In a comparison of our online versus in-class training courses on CAPI, we found that a greater percentage of students were women for the MOOCs (43\%) than the in-class training conducted 
by ADB (36\%). This could be attributed to factors such as flexibility of MOOC timing or fewer social constraints. Similarly, more than $78 \%$ of our students were from countries that are classified as low-income or lower middle-income economies by the World Bank. ${ }^{14}$

(4) Communication is vital for the success of MOOCs. One of the big advantages of in-class training is the human connection that an instructor can more easily form with her/his students. This helps sustain the interest of students over a longer duration and also brings in a certain level of accountability. It is somewhat harder to accomplish when a switch is made to an online platform. The instructor should not only be responsive to student concerns on a near-realtime basis, but should also be flexible enough to respond to queries over multiple channels-discussion forums, individual emails, or video calls. Furthermore, the platform should also have a facility for students to interact with each other so that learning is more dynamic, participatory, and collaborative. In our course, a discussion forum was the single most important element of interacting with students, and was well received.

(5) Mechanisms to incentivize students at the beginning of the course and those not making progress over a 2-week period must be considered. Reminders about deadlines strongly incentivize students to hit the finish line; as such, all MOOCs should set up a plan to send regular reminders and keep students informed. In our case, those who reached at least Module 4 by the time reminders pertaining to course deadlines were sent out were more likely to finish the course. The completion rate is rather stable from Module 4 onward, and the observed drops in completion between Module 1 and Module 3 are most likely attributable to the increase in complexity of the content.

(6) Reaching out to a wider audience requires course content to be fully translated into multiple languages. A starting point could be the six official languages of the United Nations: Arabic, Chinese, English, French, Russian, and Spanish. This would open up the MOOCs to students from non-English speaking regions and further incentivize course completion.
(7) For future rounds, it is worth exploring the possibility of making all modules available from the beginning or offering an open-ended course. This would give fast learners the opportunity to finish the course even sooner. Nonetheless, releasing all the modules ahead runs the risk of intimidating some students who might get a preview of future, more complicated modules, potentially deterring them from completing the course altogether. While an open-ended course offers more flexibility, evidence points toward lower completion rates.

(8) In terms of platform preference, CSPro was appreciated because it makes questionnaire design possible in offline mode, whereas Survey Solutions requires an internet connection to program and design a questionnaire. On the other hand, Survey Solutions was viewed favorably due to the relative ease with which a questionnaire can be set up. Further, Survey Solutions possesses a "Geography" feature that allows users to utilize offline base maps for GPS recording and area tracing.

(9) For future rounds, it might be worthwhile to allow students to register for only one of the two courses. While taking both courses simultaneously proved to be beneficial to certain students, the attrition rate was higher for this cohort, possibly because they felt overburdened from the course load.

(10) The number of notifications sent to students matters. Learners that receive an excessive amount of emails from the MOOC instructors and/or administrators may stop reading them.

14 For 2020, the World Bank defines low-income economies as those with a gross national income per capita of \$1,025 or less in 2018; and lower middle-income economies as those with a gross national income per capita between $\$ 1,026$ and $\$ 3,995$. World Bank. World Bank Country and Lending Groups. http://datahelpdesk.worldbank.org/knowledgebase/articles/906519. 
About the Asian Development Bank

ADB is committed to achieving a prosperous, inclusive, resilient, and sustainable Asia and the Pacific, while sustaining its efforts to eradicate extreme poverty. Established in 1966, it is owned by 68 members49 from the region. Its main instruments for helping its developing member countries are policy dialogue, loans, equity investments, guarantees, grants, and technical assistance.

ADB Briefs are based on papers or notes prepared by ADB staff and their resource persons. The series is designed to provide concise, nontechnical accounts of policy issues of topical interest, with a view to facilitating informed debate. The Department of Communications administers the series.

Note: In this publication, “\$” refers to United States dollars.
The views expressed in this publication are those of the authors and do not necessarily reflect the views and policies of ADB or its Board of Governors or the governments they represent. ADB encourages printing or copying information exclusively for personal and noncommercial use with proper acknowledgment of ADB. Users are restricted from reselling, redistributing, or creating derivative works for commercial purposes without the express, written consent of ADB.

Asian Development Bank 6 ADB Avenue, Mandaluyong City 1550 Metro Manila, Philippines

Tel +6326324444

Fax +6326362444

www.adb.org/publications/series/adb-briefs

\section{(c) (1)}

(C) 2020 ADB. The CC license does not apply to non-ADB copyright materials in this publication.

https://www.adb.org/terms-use\#openaccess http://www.adb.org/publications/corrigenda pubsmarketing@adb.org 